\title{
Estudos brasileiros sobre o esporte: ênfase no esporte-educação
}

\author{
Claudio Kravchychyn* \\ Walcir Ferreira Lima** \\ Amauri Aparecido Bássoli de Oliveira*** \\ Ieda Parra Barbosa-Rinaldi**** \\ Larissa Michelle Lara****
}

\begin{abstract}
Resumo: Essa resenha descreve e analisa Estudos brasileiros sobre o esporte: ênfase no esporte-educação, de Manoel José Gomes Tubino. A obra evidencia o esporte contemporâneo e o processo de consolidação efetiva de seus princípios. Por meio de um abrangente relato histórico dos movimentos esportivos internacionais que influenciaram as políticas públicas do esporte brasileiro, o autor propõe ações para a consolidação dos princípios do esporte-educação, os quais considera o alicerce fundamental para a estrutura esportiva brasileira.
\end{abstract}

Palavras-chave: esporte. educação. educação física.

O professor Manoel José Gomes Tubino (1939-2008) foi uma das personalidades mais atuantes no cenário da Educação Física brasileira. Doutor em Educação Física pela Universidade Livre de Bruxelas e em Educação pela Universidade Federal do Rio de Janeiro (UFRJ), livre-docente pela Universidade Estadual do Rio de Janeiro (UERJ), ocupou cargos públicos, como a presidência do Conselho

\footnotetext{
'Professor do Departamento de Educação Física da Universidade Estadual de Maringá - UEM claudiokrav@gmail.com

"Professor do Departamento de Educação Física da Faculdade Metropolitana de Maringá UNIFAMMA d-u-la@hotmail.com

"'Professor do Departamento de Educação Física da Universidade Estadual de Maringá - UEM amauribassoli@gmail.com

"*..Professora do Departamento de Educação Física da Universidade Estadual de Maringá UEM parrarinaldi@hotmail.com

-..."Professora do Departamento de Educação Física da Universidade Estadual de Maringá UEM Imlara@uem.br
} 
Nacional de Desportos (CND), do Instituto Nacional de Desenvolvimento do Esporte (INDESP) e da Fédération Internacionale d'Education Physique (FIEP). Na sua trajetória acadêmica publicou, em vida, 20 livros e mais de 300 artigos e resumos.

O $21^{\circ}$ livro de Tubino intitulado Estudos brasileiros sobre o esporte: ênfase no esporte-educação, eleito para essa resenha, é resultante de solicitação do Ministério do Esporte ao referido autor, escrito no ano de sua morte e publicado postumamente, em 2010. A obra é organizada em quatro etapas, chamadas por Tubino de estudos, nas quais ele retoma o processo histórico do esporte, apresenta debates e leis oriundos de seu processo de intelectualização, sugere caminhos possíveis para o reconhecimento efetivo dessa manifestação cultural como meio de educação e compartilha com o leitor seus conhecimentos e sua experiência na gestão esportiva. Percebe-se, assim, o esmero do autor em fundamentar suas propostas para o esporte brasileiro, enfatizando o esporte-educação como pilar de uma consolidação - na prática - dos conceitos do esporte contemporâneo.

No primeiro estudo intitulado "Pesquisa e análise crítica sobre o conceito atual das manifestações esportivas", o autor discute o esporte historicamente a partir do esporte antigo, do esporte moderno e do esporte contemporâneo. Tubino descreve o esporte antigo como práticas pré-esportivas que, desenvolvidas por civilizações remotas como chinesa, egípcia, etrusca, hitita e japonesa, serviram para a sobrevivência humana por meio de natação, corrida, caça, entre outras, e para preparações voltadas às guerras utilizando-se de marchas, caminhadas e esgrima. Discute os Jogos Gregos e os Jogos Olímpicos da Antiguidade, sendo estes últimos considerados os primeiros fatos esportivos, sucedidos por escassas manifestações na Idade Média e Renascença e por práticas esportivas que envolviam apostas (corridas, lutas e provas de remo), nos séculos XVIII e XIX.

$\mathrm{O}$ autor esclarece que o esporte moderno foi criado a partir de 1820, quando o inglês Thomas Arnold codificou os jogos existentes 
com regras e competições, dando origem ao Associacionismo Inglês. Recebendo grande estímulo em 1896 (Atenas), com a restauração dos Jogos Olímpicos por Pierre de Coubertin, o esporte moderno consolida os princípios da ética esportiva por meio do conceito de Fair Play, bem como do amadorismo (defesa da aristocracia contra a prática popular do esporte). O ideário olímpico - com base na ética e no associacionismo - começou a se romper em 1936 (Berlim), com a tentativa de Hitler em provar a suposta supremacia ariana, prosseguindo em 1952 (Helsinque), quando os Jogos foram transformados em palco da chamada Guerra Fria, quadro que se estendeu por várias edições posteriores. O uso político-ideológico do esporte prosseguiu com manifestações como a do Movimento Black Power por atletas negros norte-americanos (México, 1968), além de sequestros e assassinatos de atletas israelenses (Munique, 1972) e boicotes (Montreal, 1976, Moscou, 1980 e Los Angeles, 1984). O autor afirma que tais fatos, somados ao enfraquecimento da ética esportiva - vítima de ilícitos como o dopping - e ao que denomina "chauvinismo da vitória", submeteram o Olimpismo a uma grande decadência.

Tubino considera que o quadro esportivo acima descrito gerou reações que desencadearam na criação do Movimento Esporte para Todos (EPT), nos manifestos das organizações internacionais (Manifesto do Esporte, 1968; Manifesto Mundial da Educação Física - FIEP, 1970; Carta Europeia de Esporte para Todos, 1975; Manifesto do Fair Play, 1975; Carta de Paris, 1976), bem como na adesão da intelectualidade às questões do esporte (sociólogos, filósofos, cientistas políticos, entre outros), que formaram as bases do Esporte Contemporâneo. Tubino considera, ainda, a Carta Internacional de Educação Física e Esporte (UNESCO, 1978) como marco do reconhecimento das práticas esportivas como direito de todos, rompendo com a perspectiva anterior, que privilegiava os talentosos e anatomicamente indicados. Em relação ao Brasil, o autor atribui à Comissão de Reformulação do Esporte Brasileiro - presidida por ele, em 1985 - a ampliação da compreensão das manifestações esporte-educação, esporte-participação (lazer) e esporteperformance na realidade esportiva nacional. Enfatiza, também, que 
a Constituição de 1988 e a Lei Zico (Lei no 8.672/1993) contemplaram, respectivamente, $\mathrm{o}$ direito de cada um às práticas esportivas formais e não-formais e o reconhecimento das manifestações esportivas.

$\mathrm{O}$ autor afirma que, diante dos preceitos legais, o Governo Federal e os Governos Estaduais passaram a incluir o esporte nas suas atividades programáticas, instituindo Secretarias, Diretorias e Departamentos com responsabilidades sobre o esporte-educação, o esporte-participação e o esporte-rendimento, mas aponta limitações para o desenvolvimento do esporte nessa perspectiva "pela dificuldade de integração de papéis dos diversos segmentos em diferentes níveis de ação pública" (p. 30). Diante do problema, Tubino estabelece algumas ações para o papel do Estado diante do esporte, pautadas na formulação da Política Nacional do Esporte, no fomento ao esporte social, na mediação no esporte de rendimento, no desenvolvimento de infraestrutura, recursos humanos e fomento das Ciências do Esporte. É enfático ao afirmar que embora o entendimento do esporte esteja em consonância com o status conceitual internacional, permanece a necessidade de se definir o esporte como questão de Estado no Brasil.

No segundo estudo, "Elementos de superação do conceito das manifestações esportivas presentes na lei vigente que abranjam o esporte e sua totalidade", há preocupação específica do autor com a ampliação dos conceitos legais a partir de novos fatos esportivos. Daí apresentar sua percepção do esporte contemporâneo e visão do esporte brasileiro no contexto internacional. Entende que o esporteeducação (voltado para a formação da cidadania) se organiza em esporte educacional e esporte escolar. O primeiro, como entende, é aquele que pode ser praticado por crianças e adolescentes dentro e fora da escola, tendo como referência os princípios da inclusão, participação, cooperação, co-educação e co-responsabilidade. Já o segundo é, para ele, o praticado por jovens com algum talento para a prática de esportes e que, embora subentendido como competitivo, não prescinde da formação para a cidadania. 
O esporte-lazer (esporte-participação, esporte de tempo livre, entre outras denominações), também integrante das reflexões de Tubino, tem como princípios o prazer e a inclusão, sendo praticado com regras oficiais, criadas ou adaptadas. O esporte-desempenho (esporte performance, esporte institucionalizado) tem como objetivos principais a obtenção de vitórias, recordes e compensações financeiras, tendo como princípios a superação e o desenvolvimento esportivo e como subdivisões o rendimento e o alto rendimento.

Tubino apresenta também nesse estudo uma classificação esportiva contemporânea e a relação de Movimentos Esportivos em âmbito mundial (correntes esportivas). Esportes: Tradicionais, de Aventura/na Natureza/Radicais, das Artes Marciais, de Identidade Cultural, Intelectivos, com Motores, com Música, com Animais, Adaptados, Militares e Derivados de Outros Esportes. Movimentos Esportivos: Mundiais (Esporte Para Todos, Movimento Olímpico Internacional e Movimento pelo Fair Play), Continentais/ Regionais (Africano, Asiático, Centro-Americano e do Caribe, da Oceania, Europeu, Mediterrâneo, Pan-Americano, Sul-Americano), de Identidade Cultural (da Comunidade Britânica, dos Países de Língua Portuguesa, Ibero-Americano, Maccabi) e Especiais (de Deficientes, dos Esportes Radicais, Militar, Universitário). Para ele, o Quadro Internacional Esportivo oferece oportunidades para avaliações, comparações e até mesmo interferências nas políticas nacionais.

Em análise do saldo dos trabalhos da Comissão de Reformulação do Esporte Brasileiro (1985), que teve como base a Carta Internacional de Educação Física e Esporte da Unesco (1978), Tubino percebe avanços em seus cinco pontos prioritários: a reformulação do esporte e sua natureza, a necessidade de redefinição de papéis nos diversos segmentos em relação ao esporte, as mudanças jurídicoesportivo-institucionais, a carência de recursos humanos, físicos e financeiros e a insuficiência de conhecimentos científicos aplicados ao esporte. As conquistas da Constituição de 1988 e da Lei Zico foram incrementadas na Lei Pelé (Lei no 9.515/1998), que além de manter no texto ganhos anteriores, detalha, em seu parágrafo III, 
art. $3^{\circ}$, as manifestações esporte-educação, esporte-participação e esporte-rendimento. Segundo o autor, essa continuidade promoveu importantes programas federais esportivo-sociais, os quais trouxeram a inclusão de indivíduos com menor aptidão física e/ou técnica para as ações do Estado. Conclui essa parte recomendando a continuidade da ampliação dos conceitos relativos ao esporte contemporâneo para a formulação das próximas leis do esporte, estruturação de políticas específicas a cada corrente e atenção/proteção do Estado ao esporte social (esporte educação e esporte-lazer), considerando os Movimentos Esportivos existentes.

No terceiro estudo, "Relação do esporte com a educação evidenciando fatores que possam incidir sobre a conceituação, organização e realização de competições/jogos escolares para subsidiar a construção do novo sistema", Tubino centra sua atenção no esporte educacional, especificamente em sua forma de desenvolvimento e estímulo junto à comunidade estudantil. No debate sobre o esporte e suas relações com a educação, passando por teorias epistemológicas, o estudioso retoma conceitos de intelectuais como Noel-Baker, Maheu, Cagigal e Haag, os quais defendem as várias possibilidades de crescimento humano e educação a partir do meio esportivo. Como aponta Tubino, o esporte-educação, numa perspectiva sistêmica, sempre estará relacionado a manifestações do esporte-lazer e esporte-desempenho, e vice-versa, podendo ser, inclusive, base para o desenvolvimento de outras manifestações.

Diante da importância dada ao esporte-educação - acima evidenciado como pilar para o desenvolvimento esportivo do país -, o autor recapitula as leis que regeram o esporte brasileiro desde a década de 1960, e relata que mesmo sem referências jurídicas, as práticas esportivas estudantis reproduziam o esporte-desempenho, reforçando a pirâmide esportiva, quadro que somente seria modificado por meio da Constituição Federal de 1988. Os Jogos Escolares Brasileiros deveriam servir à pirâmide seletiva, mas algumas ações pontuais da SEED/MEC e do CND (então presidido por Tubino), como a proibição da participação de atletas federados, 
provocaram inúmeros debates em nível nacional. Em 1989, os Jogos Escolares foram apoiados em princípios sócio-educativos, embora isso não tenha ocorrido nos anos posteriores.

$\mathrm{O}$ autor retoma a Lei Zico para enfatizar o seu art. $3^{\circ}$, inciso I, que conceitua o esporte educacional como a manifestação que, por meio dos sistemas de ensino e das formas assistemáticas de educação, evitando a seletividade e a hipercompetitividade de seus praticantes, tem a finalidade de alcançar o desenvolvimento integral e a formação para a cidadania e o lazer. Tubino afirma que, a partir da nova perspectiva, a instituição de Programas como Esporte Solidário, Esporte na Escola e Segundo Tempo proporcionou a efetiva ação de inclusão social por meio do esporte.

Ainda com relação à legislação, o autor destaca a Lei Agnelo Piva (Lei no 10.264/2004), que destinou 2\% da arrecadação bruta de concursos lotéricos ao esporte, beneficiando o Comitê Olímpico Brasileiro (COB) e o Comitê Paraolímpico Brasileiro (CPB), com a prerrogativa de investimento de $15 \%$ do montante recebido no esporte escolar (10\%) e no esporte universitário (5\%). Afirma, ainda, que essa lei possibilitou ao esporte-educação, na sua manifestação esporte escolar, o aporte financeiro que historicamente faltava ao desenvolvimento esportivo do país.

A partir do desenvolvimento desse terceiro estudo, Tubino apresenta indicações para a atualização das políticas públicas no que diz respeito ao esporte-educação. Reitera a necessidade do esporte se transformar em questão de Estado no Brasil, de manutenção e aprimoramento de programas sociais esportivos, da distinção entre esporte educacional (também como meio da Educação Física escolar) e esporte escolar (que não pode perder o sentido de formação para a cidadania), de se propiciar aos praticantes as vivências defendidas teoricamente e de não se perder a constante conexão com o contexto do esporte brasileiro (acompanhando mudanças periódicas).

No quarto estudo, intitulado "Pesquisa e análise crítica sobre a relação do nexo esporte-educação com os jogos escolares", a atenção volta-se para os elos entre esporte e educação, especialmente 
para o foco nos eventos esportivos. Sinteticamente, Tubino discute o esporte-educação no século XX, a partir de cinco períodos históricos: período da não existência do esporte-educação, período da ênfase no esporte-desempenho (vigência do ciclo militar, tutela e paternalismo do Estado), período da reflexão sobre o esporteeducação (volta da democracia, JEBs sem atletas federados), período do obscurantismo no esporte-educação (involução no governo Itamar Franco, falta de recursos) e período da retomada da reflexão no esporte-educação (atual, consolidação do esporte como direito de todos, iniciativa governamental na implementação de programas sociais de esporte e lazer).

O autor destaca que o esporte escolar e, por consequência, os jogos escolares no Brasil, denotam uma experiência única no mundo devido à diversidade contextual, cultural, demográfica, geográfica e de quantidade de participantes. Assim, propõe formas possíveis de jogos escolares, referenciadas em processos de formação para a cidadania: os jogos cooperativos, cuja essência contém as práticas cooperativas e sociomotrizes como aspectos coletivos (com experiências de sucesso no Brasil) e o desenvolvimento de uma educação olímpica, com o desenvolvimento do Fair Play e vivências referenciadas nos símbolos olímpicos.

No intuito de descrever e analisar o esporte contemporâneo por meio da memória dos movimentos esportivos internacionais, Tubino volta-se para a descrição de fatos sem se preocupar em situá-los em seu jogo tensional, a exemplo das polêmicas que envolveram o Esporte para Todos no Brasil, conhecido como EPT, quando o autor apenas reforça a ideia de que o EPT defendeu, desde seu início, a democratização das práticas esportivas. Outro aspecto evidenciado em sua obra e que marca, por vezes, carência de viés político de análise, diz respeito à visualização da UNESCO como órgão que passa a perceber que a atividade física/esportiva era um "excelente meio de educação permanente", o que teria influenciado os elos entre esporte e educação sem, contudo, considerar os elementos motivadores dessa relação. 
Fiel ao seu perfil de gestor esportivo, Tubino apresenta, nessa obra, uma visão "macro" e uma perspectiva sistêmica do esporte mundial e nacional, que em alguns momentos mais tensos da educação física nacional the renderam críticas no ambiente acadêmico, em especial nas mesas redondas de eventos da área. Foi comum, principalmente na década de 1980, a ação de intelectuais que se preocuparam em eleger uma ou outra manifestação do esporte como ideal, sobretudo nos ambientes escolar e educacional, o que acabava por desaprovar as demais, como o esporte institucionalizado. Tubino, por sua vez, situou historicamente, classificou e atribuiu importância a todas as manifestações esportivas. Tal pluralidade é reconhecida nessa e em outras obras do autor que tratam das políticas públicas para o esporte, embora nem sempre consensuadas pela academia como a melhor leitura da realidade esportiva.

Azevedo e Gomes Filho (2011) apontam vantagens na classificação apresentada por Tubino (esporte-educação, esporteparticipação e esporte-performance ou de rendimento), e afirmam ser ela claramente ética, pois foca a oportunidade da prática quando trata do direito ao esporte, do esporte para todos e da inclusão por meio do esporte. Ainda, segundo os autores, Tubino entende que o esporte-participação - mais do que o esporte-educação e o esporterendimento - é a dimensão que mais oportuniza a prática de esportes como direito de todo cidadão. Acaba por estabelecer convergência com os autores que criticam a aplicação do modelo de esporte de rendimento em contextos educacionais ao denunciar que há nele a exacerbação do agon e a atro?a do ludens, ou lúdico.

Já Stigger (2005, p. 76), referindo-se à classificação de Tubino (apresentada em 1992 e retomada nesta obra), reconhece sua importância, lembrando que ela foi incorporada a leis importantes como a Lei Zico e a Lei Pelé, alvos de muitas discussões e debates. Porém, embora ressalte o preenchimento de uma lacuna, já que até então não havia uma formulação efetivamente reconhecida pela área, o referido autor argumenta que essa repercussão, de certa forma, vulgarizou sua utilização, tanto nos discursos recorrentes quanto nas diferentes situações em que foi aplicada. Entende que - 
provavelmente sem intenção de Tubino - essa classificação do esporte trata-se de "categorias de pensamento construídas pelo pesquisador que, apesar de ajudarem a pensar a realidade, não têm a pretensão de se confundirem com ela".

De qualquer forma, os apontamentos que o pesquisador traz no sentido de orientar o pensamento sobre o esporte contemporâneo e as contribuições de seu pensamento à educação física brasileira reforçam a crença numa educação física de intervenção social, que transcende a mera esportivização rumo ao diálogo possível e necessário com o campo da educação. Diante dos apontamentos históricos que o autor faz, bem como de suas reflexões sobre os movimentos nacionais e internacionais e sua influência na legislação e nas ações governamentais, que precisam ser transformados em pressupostos para as ações pedagógicas no esporte-educação, entendemos que a obra pode referenciar o trabalho de gestores do esporte (nos diversos níveis), de professores de educação física atuantes como educadores (no ambiente escolar e extraescolar) e de técnicos esportivos (também educadores) na perspectiva de construção de um pensamento para além do fazer esportivo.

Sendo o autor referência em nível internacional e uma das personalidades de maior destaque no cenário da gestão esportiva nacional, temos que considerar as ideias e proposições apresentadas nessa obra quando discutirmos a política pública esportiva nacional, independentemente da corrente e/ou ideologia que ela carrega. Daí avaliarmos que o legado biográfico e bibliográfico deixado por Tubino foi imprescindível para o nível em que se encontra a educação física e seus profissionais em nosso país, trazendo contribuições para o desenvolvimento e qualificação da área. 
Brazilian studies about sport: the sport education emphasis

Abstract: This review describes and analyzes the book Brazilian studies about sport: the sport education emphasis, by Manoel José Gomes Tubino. The work marks the contemporary sport practice and the process of effective consolidation of its principles. Through a wide historical description of the international sports movements which influenced Brazilian sports public policies, the author proposes actions for sportseducation principles consolidation, which he considers to be the key basis to Brazilian sports structure.

Key words: sports. education. physical education.

Estudios brasileños sobre el deporte: énfasis en lo deporte-educación

Resumen: Esa reseña describe y analiza Estudios brasileños sobre el deporte: énfasis en lo deporteeducación, de Manoel José Gomes Tubino. El obra pone en evidencia el deporte contemporáneo y el proceso de consolidación efectiva de sus principios. A través de un amplio relato histórico de los movimientos deportivos internacionales que influyeron en las políticas públicas del deporte brasileño, el autor propone acciones para la consolidación de los principios del deporte-educación, que considera la base fundamental para la estructura del deporte brasileño.

Palabras clave: deporte. educación. educación física. 


\section{REFERÊNCIAS}

AZEVEDO, Marco Antonio Oliveira; GOMES FILHO, Arnóbio. Competitividade e inclusão social por meio do esporte. Rev. Bras. Ciênc. Esporte, Florianópolis, v. 33, n. 3, p. 589-603, jul./set. 2011.

STIGGER, Marco Paulo. Educação Física, esporte e diversidade. Campinas: Autores Associados, 2005.

TUBINO, Manoel José Gomes. Estudos brasileiros sobre o esporte: ênfase no esporte-educação. Maringá: Eduem, 2010.

Endereço para correspondência:

Universidade Estadual de Maringá - Departamento de Educação Física

Av. Colombo, 5.790 - Bloco M-06 - Jardim Universitário

Maringá - Paraná - Brasil

CEP 87020-900

Recebido em: 04.05.2012

Aprovado em: 28.05.2012

Movimento, Porto Alegre, v. 18, n. 02, p. 339-350, abr/jun de 2012. 
